\title{
INFLUÊNCIA DA ESPESSURA E ADIÇÃO DE FIBRAS EM COMPÓSITOS EMPREGADOS EM PAREDES DE CONCRETO
}

\author{
Influence of thickness and addition of fibers in composites employed in \\ concrete walls
}

\author{
Mariana Zucchi Vargas ${ }^{1}$; Francine Padilha ${ }^{2}$; Felipe Ril ${ }^{1}$; Cristina Vitorino da Silva ${ }^{1}$
}

\footnotetext{
${ }^{1}$ Universidade Regional Integrada do Alto Uruguai e das Missões - URI Erechim, E-mail: marianazv03@ gmail.com; felipe.ril@hotmail.com; cristina@uricer.edu.br

${ }^{2}$ Universidade Federal de Santa Catarina - PPGEC/UFSC, Florianópolis, SC. E-mail: francine. padilha1609@gmail.com
}

Data do recebimento: 30/01/2020 - Data do aceite: 09/04/2020

RESUMO: Permitindo realizar com agilidade e economia obras em grande escala, o sistema executivo de paredes de concreto moldadas in loco surge com um grande aceite das construtoras. Buscando melhorar as propriedades do concreto autoadensável empregado neste sistema, tem-se incorporado fibras à mistura. A adição de fibras tem sido uma prática adotada por construtoras da região de Erechim, RS, porém sem padronização e estudos referentes aos teores utilizados. Desta forma, este estudo visa analisar a atuação de diferentes teores de fibras de polipropileno em concretos autoadensáveis, avaliando também a influência da variação da espessura de parede quanto a resistência à tração na flexão. $\mathrm{O}$ concreto foi desenvolvido considerando-se as informações coletadas sobre o método construtivo e as características das obras consumadas com o sistema na cidade de Erechim, RS. Os resultados demonstraram que para a tração na flexão existe uma tendência no aumento da resistência a esse esforço conforme o acréscimo no teor de fibra; já para o módulo de elasticidade, obteve-se o comportamento inverso. Em relação à espessura das paredes, as placas de $80 \mathrm{~mm}$ de espessura demostraram maior resistência, por provirem de uma mistura mais homogênea, uma vez que para tais placas a quantidade de fibras adicionada foi menor.

Palavras-chave: Paredes de Concreto Moldadas in loco. Fibras de Polipropileno. Concretos Autoadensáveis. Espessura de Parede. Resistência à Tração na Flexão. 


\begin{abstract}
Allowing large-scale work to be carried out with agility and economy, the constructive method of cast in place concrete walls experiences great acceptance among contractors. Seeking to improve the properties of self-compacting concrete used in this system, fibers have been incorporated into the mixture. The addition of fibers has been a practice adopted by construction companies in the region of Erechim, RS, however, without standardization and studies regarding the contents used. Thus, this study aims to analyze the performance of different levels of polypropylene fibers in self-compacting concretes, also evaluating the influence of the variation in wall thickness in terms of tensile strength in flexion. The concrete was developed considering the information collected about the construction method and the characteristics of the works completed with the system in the city of Erechim, RS. The results showed that for flexion tensile stresses there is a tendency to increase the resistance to this effort according to the increase in fiber content; for the modulus of elasticity, the opposite behavior was obtained. Regarding the thickness of the walls, the $80 \mathrm{~mm}$-thick plates showed greater resistance, as they come from a more homogeneous mixture, since for such plates less amount of fibers were added.
\end{abstract}

Keywords: Cast in Place Concrete Walls. Polypropylene Fibers. Self-Compacting Concretes. Wall Thickness. Flexure Tensile Strength.

\section{Introdução}

A busca pela otimização da mão de obra mediante a adoção de tecnologias viáveis faz com que as obras com paredes de concreto ganhem espaço como metodologia de execução para as novas edificações. As obras executadas com paredes de concreto moldadas in loco auxiliam empresas de médio e grande porte a acelerarem o cumprimento dos cronogramas, diminuindo o tempo de execução e os custos totais das edificações.

O método construtivo com paredes de concreto moldadas in loco ganhou impulsão após a publicação da NBR 16055 (ABNT, 2012), que engloba todos os procedimentos ligados a execução e elaboração do projeto para execução do sistema. Para que se garanta a qualidade e segurança da edificação, todos os requisitos mínimos da norma devem ser seguidos. A metodologia do sistema é baseada na industrialização dos processos e, para garantir os prazos e custos planejados, a qualidade e a evolução da obra devem ser monitoradas constantemente.

Sabe-se que o concreto apresenta boa resistência a esforços de compressão, mas deixa a desejar quanto a sua capacidade de resistir a tensões de tração. Segundo Figueiredo (2011), o concreto possui um comportamento frágil e baixa capacidade de deformação antes de entrar em ruptura, quando sujeito a esforços de tração.

Recentemente, a adição de fibras em concretos tem gerado o aumento da resistência e da tenacidade do material. A tecnologia possibilita a execução de projetos estruturais mais avançados e o aperfeiçoamento de estruturas já existentes. Mesmo que o mercado de concretos com adição de fibras ainda seja pequeno em relação à produção 
total de concreto, já é notório o aumento da utilização dessa adição sintética (MEHTA; MONTEIRO, 2014; SRIDHAR; PRASAD, 2018).

As fibras estão sendo utilizadas em vários setores da construção civil, como na fabricação de telhas, uso em pavimentações, painéis de vedação vertical, dentre outros. De modo geral, estas utilizações buscam minimizar deficiências dos compósitos convencionais que não atingem o desempenho esperado (JUNIOR DOBBIN; ROCHA, 2011).

A adição de fibras no concreto utilizado para produção de paredes moldadas in loco é uma prática que está sendo adotada pelas empresas construtoras, mas a falta de padronização e estudo dos teores utilizados são visíveis necessidades de mercado para evitar manifestações patológicas. No Brasil, a adição de fibras em misturas de concreto se dá basicamente de forma empírica, uma vez que os teores utilizados são praticamente fixos e sem qualquer controle de qualidade (FIGUEIREDO, 2011).

O conhecimento dos materiais que irão ser adotados e do processo executivo são premissas para que se consiga alcançar os resultados esperados. Dentro desse contexto, a busca pela correta utilização dos teores de fibras adicionados à mistura para ganho de resistência à tração das paredes de concreto é um dos objetivos principais deste trabalho.

\section{Material e Métodos}

Para a realização deste estudo foram realizadas duas etapas. Na etapa 1 , fez-se o levantamento de informações de obras executadas com paredes de concreto na cidade de Erechim-RS, para posteriormente realizar o programa experimental (etapa 2), levando em conta as informações obtidas na etapa anterior. O programa experimental consiste em destacar os fatores controláveis que são objetivo de estudo e as variáveis de resposta. Também são citados os materiais utilizados e suas características, e os procedimentos baseados em normativas para a execução dos ensaios contidos no programa experimental.

\section{Levantamento de informações de obras com paredes de concreto na cidade de Erechim-RS}

A coleta de informações das obras em execução foi realizada com a utilização de um formulário padrão (Tabela I), elaborado a partir das principais exigências da normativa NBR 16055 (ABNT, 2012), tendo como foco as propriedades do material utilizado, o tipo de forma e a adição de fibras. A Tabela I demonstra as informações obtidas com as empresas consultadas na cidade de Erechim.

Tabela I - Informações das obras executadas com paredes de concreto moldadas in loco na cidade de Erechim-RS

\begin{tabular}{|c|c|c|}
\hline ITEM VERIFICADO & OBRA 1 & OBRA 2 \\
\hline Fck - utilizado & $25 \mathrm{MPa}$ & $25 \mathrm{MPa}$ \\
\hline Traço do concreto & $*$ & $*$ \\
\hline Flow test & $700 \mathrm{~mm}$ & $700 \mathrm{~mm}$ \\
\hline $\begin{array}{l}\text { Tempo de montagem } \\
\text { das formas por andar }\end{array}$ & 2 dias & 2 dias \\
\hline Prazo de desforma & $1 \mathrm{dia}$ & 1 dia \\
\hline Tipo de fibra & Polipropileno & Polipropileno \\
\hline Teor da adição de fibra & $600 \mathrm{~g} / \mathrm{m}^{3}$ & $600 \mathrm{~g} / \mathrm{m}^{3}$ \\
\hline Desmoldante utilizado & $*$ & $*$ \\
\hline Espessura das paredes & $12 \mathrm{~cm}$ & $12 \mathrm{~cm}$ \\
\hline $\begin{array}{l}\text { Ensaio do concreto } \\
\text { endurecido } \\
\text { (compressão uniaxial) }\end{array}$ & 7 e 28 dias & 7 e 28 dias \\
\hline $\begin{array}{l}\text { Quantidade de CPs } \\
\text { moldados }\end{array}$ & $\begin{array}{c}6 \text { a cada } 30 \\
\mathrm{~m}^{3}\end{array}$ & 6 a cada $30 \mathrm{~m}^{3}$ \\
\hline $\begin{array}{l}\text { Quantidade }\left(\mathrm{m}^{3}\right) \\
\text { de concreto por } \\
\text { pavimento }\end{array}$ & $75 \mathrm{~m}^{3}$ & $75 \mathrm{~m}^{3}$ \\
\hline
\end{tabular}

* As empresas não permitiram divulgação desses dados. 
O formulário foi elaborado com base em entrevistas realizadas com as empresas que executam o sistema de paredes de concreto moldadas in loco, de modo a proporcionar o desenvolvimento de um concreto que tenha propriedades muito próximas ao que está sendo utilizado pelas empresas construtoras da região.

Dentre as informações, obteve-se uma referência de resistência na ordem de $25 \mathrm{MPa}$, e uma referência no teor de adição de fibra de $600 \mathrm{~g} / \mathrm{m}^{3}$. A partir destas informações básicas este estudo foi desenvolvido.

\section{Programa Experimental}

O programa experimental deste trabalho, de acordo com a Figura 1, foi planejado de forma a trabalhar com variáveis de controle para, posteriormente, por meio de tratamento estatístico pelo software STATISTICA 7.0, avaliar a influência de cada um destes fatores nas variáveis de resposta.

Foram escolhidos quatro teores de adição de fibras, tendo em vista que a empresa que fornece o material estipula uma dosagem com $600 \mathrm{~g} / \mathrm{m}^{3}$. Logo, optou-se por trabalhar com uma margem de $300 \mathrm{~g} / \mathrm{m}^{3}$ para mais e para menos, com o teor fornecido pela empresa e ainda uma quarta dosagem para se utilizar como referência para as demais, com $0 \%$ de adição.

A variação da espessura segue o prescrito pela normativa NBR 16055 (ABNT, 2012), que recomenda o mínimo de $80 \mathrm{~mm}$ para paredes internas e $100 \mathrm{~mm}$ para as paredes externas. Além disso, a maior parte das empresas construtoras da região adotam espessuras acima do que a Norma estabelece (120 mm), conforme apresentado na Tabela I. Logo, julgou-se interessante avaliar as duas espessuras ( 80 e $100 \mathrm{~mm}$ ) na pesquisa, frente às propriedades analisadas. A Tabela II apresenta as combinações utilizadas neste estudo.

Figura 1 - Programa experimental

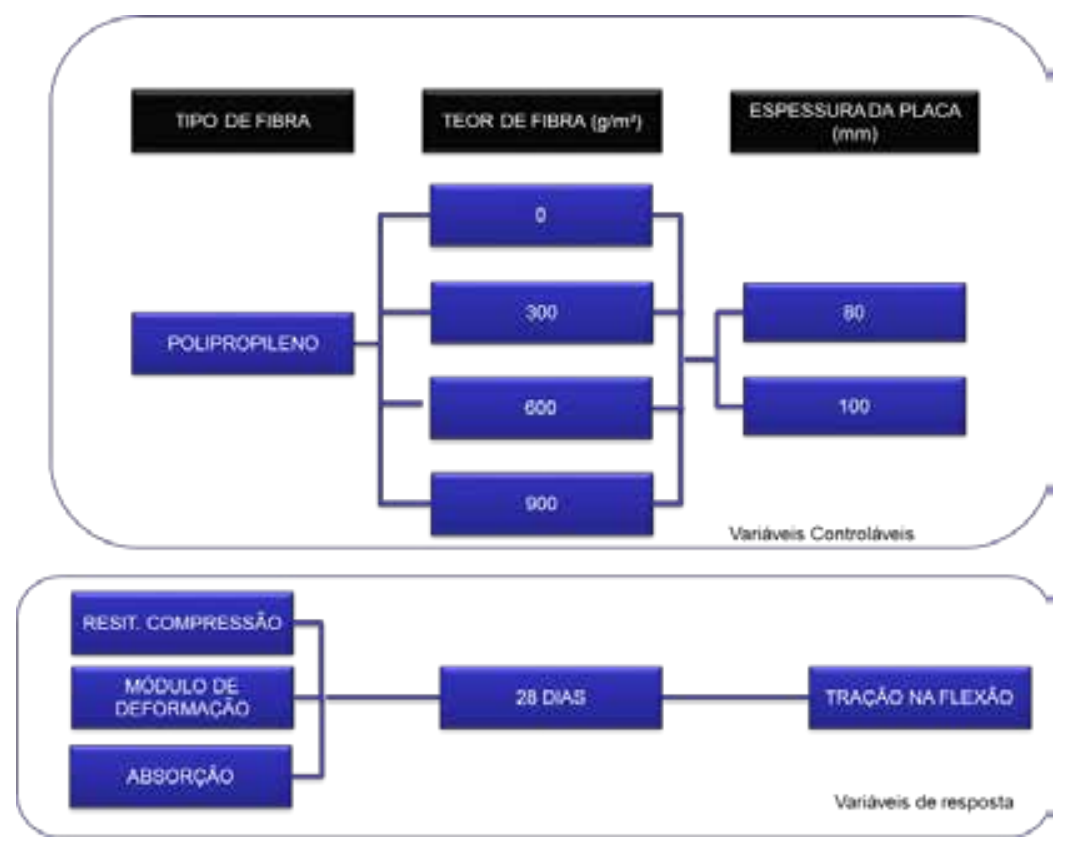


Tabela II - Combinações utilizadas

\begin{tabular}{ccc}
\hline COMBINAÇÃOO & $\begin{array}{c}\text { QUANTIDADE } \\
\text { DE FIBRA } \\
\left(\mathbf{g} / \mathbf{m}^{3}\right)\end{array}$ & $\begin{array}{c}\text { ESPESSURA } \\
\text { DA PAREDE } \\
(\mathbf{m m})\end{array}$ \\
\hline 1 & 0 & 80 \\
2 & 0 & 100 \\
3 & 300 & 80 \\
4 & 300 & 100 \\
5 & 600 & 80 \\
6 & 600 & 100 \\
7 & 900 & 80 \\
8 & 900 & 100 \\
\hline
\end{tabular}

\section{Materiais}

Nesta pesquisa foi empregado o cimento Portland CP V-ARI, com massa específica igual a $3,03 \mathrm{~g} / \mathrm{cm}^{3}$, areia natural fina com dimensão máxima característica (DMC) igual a $1,18 \mathrm{~mm}$, módulo de finura (MF) igual a 1,90 e massa específica igual a $2,62 \mathrm{~g} / \mathrm{cm}^{3}$. O agregado graúdo utilizado foi uma brita de origem basáltica, comercialmente denominada como brita 0 , com MF de 5,81, DMC de 9,5 mm e massa específica igual a $2,73 \mathrm{~g} / \mathrm{cm}^{3}$. $\mathrm{O}$ aditivo usado foi um superplastificante baseado em uma cadeia de éter policarboxílico. Para a produção dos concretos autoadensáveis foi adotado o uso de sílica ativa com massa específica de $2,05 \mathrm{~g} / \mathrm{cm}^{3}$. A Tabela III apresenta a caracterização das fibras de polipropileno que foram estudadas, segundo o fabricante.

\section{Dosagem Experimental}

Para a dosagem, buscou-se atender os parâmetros de resistência e trabalhabilidade fornecidos pelas empresas construtoras, a fim de se obter um compósito que se assemelhe ao máximo com o utilizado pelas mesmas.

Para a dosagem dos traços iniciais procurou-se trabalhar com traços previamente estudados e nesta etapa foi utilizado como referência o material de desenvolvimento de dosagens proposto por Tutikian e Dal Molin (2008). No desenvolvimento do traço optou-se por fixar a substituição do cimento pela sílica em um teor de $10 \%$ em volume, e o uso do aditivo foi fixado em um teor de $1 \%$ sobre a massa de cimento, baseando-se nas recomendações dos fabricantes em conjunto com os estudos abordados para a elaboração dos traços. O teor de argamassa dos traços foi fixado em 55\%. Após a definição dos traços, foi realizada a mistura buscando-se avaliar as propriedades do concreto no estado fresco e estado endurecido.

Para a caracterização do concreto autoadensável (CAA) no estado fresco foram realizados os seguintes ensaios: Determinação do Espalhamento e do Tempo de Escoamento ou T500 (Método do Cone de Abrams - Classe SF 2) pela NBR 15823/2 (ABNT, 2017), Determinação da Habilidade Passante (Método da caixa L - Classe PL 2) por meio da NBR 15823/4 (ABNT, 2017) e a Determinação

Tabela III - Propriedades físicas e mecânicas da fibra de polipropileno

\begin{tabular}{cccc}
\hline \multicolumn{2}{c}{ PROPRIEDADES FÍSICAS } & \multicolumn{2}{c}{ PROPRIEDADES MECÂNICAS } \\
\hline Diâmetro & $18 \mu \mathrm{m}$ & Temperatura de fusão & $160^{\circ} \mathrm{C}$ \\
Comprimento & $24 \mathrm{~mm}$ & Temperatura de ignição & $365^{\circ} \mathrm{C}$ \\
Alongamento & $80 \%$ & Resistência à tração & $300 \mathrm{MPa}$ \\
Peso específico & $0,91 \mathrm{~g} / \mathrm{cm}^{3}$ & Módulo de Young & $3000 \mathrm{MPa}$ \\
\hline
\end{tabular}


da Viscosidade Aparente (Método do funil $\mathrm{V}$ - Classe VS 1) por meio da NBR 15823/5 (ABNT, 2017).

Com a realização de todos os ensaios, o traço escolhido para o desenvolvimento do estudo foi $1: 4,5$, por cumprir todos os parâmetros de aceitação para o estado fresco e ainda atingir a classe de resistência esperada de $25 \mathrm{MPa}$. As Tabelas IV e V apresentam, respectivamente, os resultados para os ensaios em estado fresco e os parâmetros do traço utilizado nesta pesquisa.

\section{Ensaio de Resistência à Tração na Flexão}

O ensaio de tração na flexão foi realizado seguindo-se a NBR 12142 (ABNT, 2010). Para este ensaio, desenvolveu-se uma forma de 250x500x100 mm, que pode ser adaptada para as dimensões de 250x500x80 mm. Tendo em vista que o objetivo principal deste trabalho é avaliar o comportamento do concreto com a adição de fibras e a variação da espessura da parede frente aos esforços de tração na flexão, optou-se por realizar o ensaio em amostras que possuam a mesma espessura de parede interna e externa mínimas recomendada pela NBR 16055 (ABNT, 2012), sendo necessário, então, o desenvol- vimento de uma forma específica para tal. A Figura 2 demonstra a forma utilizada. Ao todo, foram moldadas 24 amostras.

Figura 2 - Forma utilizada para ensaio de resistência à tração na flexão

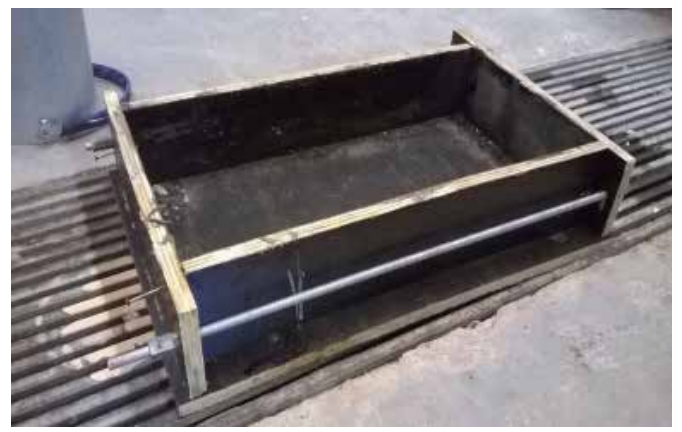

Além do ensaio de tração na flexão, foram realizados os ensaios de compressão uniaxial, módulo de elasticidade e absorção de água por capilaridade, regulamentados respectivamente pelas NBR 5739 (ABNT, 2018), NBR 8522 (ABNT, 2017) e NBR 9779 (ABNT, 2012). Todos os ensaios foram realizados em sala climatizada, com temperatura e umidade controladas (temperatura de $23{ }^{\circ} \mathrm{C} \pm 2{ }^{\circ} \mathrm{C}$ e umidade relativa do ar de $65 \% \pm 5 \%$ ). As rupturas foram efetuadas em prensa servo-hidráulica com capacidade máxima de 2000 $\mathrm{KN}$ que, juntamente a um computador com software torna possível a obtenção dos resul-

Tabela IV - Resultados ensaios em estado fresco - traço utilizado

\begin{tabular}{ccccc}
\hline \multirow{2}{*}{ TRAÇO } & $\begin{array}{c}\text { ESPALHAMENTO } \\
(\mathrm{MM})\end{array}$ & T500 (S) & $\begin{array}{c}\text { HABILIDADE } \\
\text { PASSANTE (H2/H1) }\end{array}$ & $\begin{array}{c}\text { VISCOSIDADE } \\
\text { APARENTE (S) }\end{array}$ \\
\hline $1: 4,5$ & 652,5 & 2,19 & 0,84 & 7,16 \\
\hline
\end{tabular}

Tabela V - Parâmetros do traço utilizado na pesquisa

\begin{tabular}{|c|c|c|c|c|c|c|c|c|}
\hline \multirow[b]{2}{*}{ TRAÇO } & \multicolumn{7}{|c|}{ TRAÇO UNITÁRIO DESDOBRADO } & \multirow[b]{2}{*}{$\begin{array}{c}\text { CONSUMO } \\
\text { DE CIMENTO } \\
\left(\mathrm{kg} / \mathrm{m}^{3}\right)\end{array}$} \\
\hline & cimento & aditivo & sílica & areia & brita & a/agl & $\begin{array}{c}\text { RESISTÊNCIA } \\
\text { MÉDIA AOS } 28 \\
\text { DIAS (MPa) }\end{array}$ & \\
\hline $1: 4,5$ & 0,90 & 0,01 & 0,10 & 2,02 & 2,47 & 0,52 & 32,85 & 395,33 \\
\hline
\end{tabular}


tados dos ensaios. Para o ensaio de módulo de elasticidade um extensômetro eletrônico foi incorporado à prensa, conforme a Norma regulamentadora.

\section{Resultados e Discussões}

A seguir apresentam-se os resultados obtidos, verificando a influência da adição de fibras no concreto e da espessura das paredes para o sistema construtivo em questão.

\section{Ensaio de Resistência à Compressão Uniaxial}

A Tabela VI apresenta os resultados médios obtidos nos ensaios de resistência à compressão uniaxial; a Tabela VII apresenta os resultados tratados por meio da análise de variância (ANOVA), do programa STATISTICA 7.0.

A análise estatística dos dados de resistência à compressão uniaxial indicou que a variável de controle (teor de adição de fibra) não gerou influência significativa na variável de resposta (resistência à compressão uniaxial). Ainda, verificou-se que as adições de diferentes teores de fibra não trouxeram nenhum ganho de resistência à compressão às misturas. Do mesmo modo que para Figueiredo (2011), os resultados apresentaram picos de resistência distintos e sem um padrão entre os teores de adição, os quais não devem ser relacionados com a adição das fibras de polipropileno. Assim, determina-se que o uso das fibras de polipropileno é recomendado para evitar as fissuras de retração na fase plástica dos compósitos e não para ganho de resistência à compressão (TANESSI; FIGUEIREDO, 1999; SRIDHAR; PRASAD, 2018).

Cabe salientar que, durante as moldagens para a realização deste ensaio, percebeu-se que as misturas apresentaram modificações na trabalhabilidade, conforme o aumento do teor de fibra. $\mathrm{O}$ acréscimo de fibras pode ter ocasionado em uma maior retenção de água em função da elevada superfície específica das mesmas (LIU et al.; 2019).

Tabela VI - Resistência à compressão uniaxial

\begin{tabular}{cccc}
\hline $\begin{array}{c}\text { TEORES DE FIBRAS } \\
\left(\mathbf{g} / \mathbf{m}^{\mathbf{3}}\right)\end{array}$ & $\begin{array}{c}\text { RESISTÊNCIA À COMPRESSÃo } \\
\text { MÉDIA AOS 28 DIAS (MPa) }\end{array}$ & $\begin{array}{c}\text { DESVIO } \\
\text { PADRÃO } \\
(\mathbf{M P a})\end{array}$ & $\begin{array}{c}\text { COEFICIENTE DE } \\
\text { VARIÂNCIA } \\
(\mathbf{\%})\end{array}$ \\
\hline 0 & 62,33 & 4,1900 & 6,73 \\
300 & 61,36 & 5,2183 & 8,50 \\
600 & 63,78 & 2,9900 & 4,69 \\
900 & 61,72 & 4,5661 & 7,40 \\
\hline
\end{tabular}

Tabela VII - Resistência à compressão uniaxial (ANOVA)

\begin{tabular}{ccccccc}
\hline EFEITO & SS & GDL & MS & F (CALC) & P & SIGNIFICÂNCIA \\
\hline $\begin{array}{c}\text { Teor de adição de } \\
\text { fibra }\end{array}$ & 13,81 & 3 & 4,6 & 0,275 & 0,84253 & NS \\
Erro & 301,23 & 18 & 16,74 & & & \\
\hline
\end{tabular}

GDL: graus de liberdade (n-1); MS: média simples; F(calc): valor calculado de F; P: nível de significância; S: valor significativo; NS: valor não significativo; $\mathrm{Se} \mathrm{P}<5 \%$ valor significativo 


\section{Ensaio de Absorção por Capilaridade}

A Tabela VIII apresenta os resultados médios obtidos nos ensaios de determinação da absorção de água por capilaridade. Já a Tabela IX apresenta os mesmos resultados tratados estatisticamente pela ANOVA.

Por meio dos dados da Tabela IX, pode-se perceber que o teor de adição de fibra promoveu efeitos significativos na absorção por capilaridade. A Figura 3 apresenta o efeito do teor de adição nos resultados de absorção de água por capilaridade.

Percebe-se que a absorção para os teores de $900 \mathrm{~g} / \mathrm{m}^{3}$ e $600 \mathrm{~g} / \mathrm{m}^{3}$ foi superior em relação aos concretos de referência e dosados com $300 \mathrm{~g} / \mathrm{m}^{3}$. Entre o concreto de referência (teor de adição $0 \mathrm{~g} / \mathrm{m}^{3}$ ) e o concreto dosado com $900 \mathrm{~g} / \mathrm{m}^{3}$ observou-se um aumento de, aproximadamente, $400 \%$ de água absorvida. Nota-se que, com o acréscimo no teor de fibras, os canais (entre concreto e fibra) aumentaram e facilitaram a ascensão capilar.

Outros fatores que podem ter colaborado com este efeito, assim como para Junior Dobbin e Rocha (2011), foi a redução da trabalhabilidade e da facilidade de moldagem (traço com maior teor), ocasionando uma absorção maior de água, promovendo assim um aumento na ascensão capilar do compósito.

Figura 3 - Efeito do teor de adição nos resultados de absorção de água por capilaridade

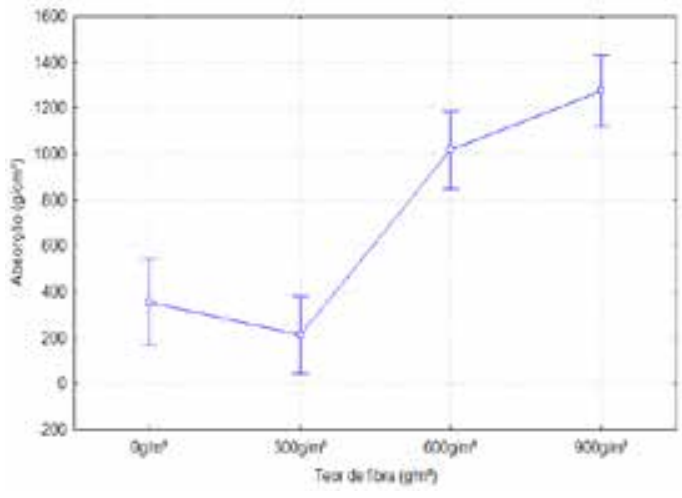

Assim como concluíram Rodrigues e Montardo (2002), a compatibilidade química e física entre as fibras e a matriz é muito importante. No caso das fibras que adsorvem água e podem causar excessiva perda de trabalhabilidade do concreto, gera-se um excesso de vazios. Ainda, pode ocorrer de algumas fibras acabarem aumentando a

Tabela VIII - Resultados médios de absorção

\begin{tabular}{cccc}
\hline $\begin{array}{c}\text { TEORES DE FIBRAS } \\
\left(\mathbf{g} / \mathbf{m}^{\mathbf{3}}\right)\end{array}$ & $\begin{array}{c}\text { ABSORÇÃO MÉDIA AOS } \\
\text { 28 DIAS }\left(\mathbf{g} / \mathbf{c m}^{\mathbf{2}}\right)\end{array}$ & $\begin{array}{c}\text { DESVIO PADRÃo } \\
\left(\mathbf{g} / \mathbf{c m}^{\mathbf{2}}\right)\end{array}$ & $\begin{array}{c}\text { COEFICIENTE DE } \\
\text { VARIÂNCIA }\end{array}$ \\
\hline 0 & 254,78 & 139,54 & $\mathbf{( \% )}$ \\
\hline 300 & 254,78 & 180,15 & 54,772 \\
600 & 1019,11 & 227,87 & 70,711 \\
900 & 1273,89 & 208,02 & 22,361 \\
& & & 16,330 \\
\hline
\end{tabular}

Tabela IX - Absorção por capilaridade (ANOVA)

\begin{tabular}{ccccccc}
\hline EFEITO & SS & GDL & MS & F (CALC) & P & SIGNIFICÂNCIA \\
\hline Teor de adição de fibra & $4,9 \mathrm{E}+07$ & 3 & 1621161 & 41,5097 & 0 & S \\
Erro & 781100 & 20 & 39055 & & & \\
\hline
\end{tabular}

DGDL: graus de liberdade (n-1); MS: média simples; F(calc): valor calculado de F; P: nível de significância; S: valor significativo; NS: valor não significativo; $\mathrm{Se} \mathrm{P}<5 \%$ valor significativo 
retenção de água em torno delas, em função da sua elevada superfície específica.

\section{Ensaio de Módulo de Elasticidade}

A Tabela X apresenta os resultados médios obtidos no ensaio de módulo de elasticidade. A Tabela XI apresenta os resultados obtidos pela ANOVA.

A análise estatística dos dados de módulo de elasticidade indicou que a variável controlável (teor de adição de fibra) gerou uma influência significativa na variável de resposta (módulo de deformação).

Ao analisar os resultados obtidos, verificou-se uma redução de $44 \%$ no módulo de elasticidade dos concretos com teor de adição de $300 \mathrm{~g} / \mathrm{m}^{3}$, comparados às amostras com $600 \mathrm{~g} / \mathrm{m}^{3}$ de fibras adicionadas, fato que deixa evidente que, quanto maior o teor de fibra adicionado, menor é o módulo de elasticidade do compósito.

Figueiredo (2011) definiu, em relação ao módulo das fibras, que as mesmas possuem módulo de elasticidade inferior ao do concreto endurecido, logo, são chamadas de fibras de baixo módulo e promovem maiores deformações aos compósitos. Esse fato justifica a crescente redução do módulo de elasticidade das matrizes cimentícias com aumento no teor de incorporação das fibras de polipropileno (SRIDHAR; PRASAD, 2018).

\section{Ensaio de Resistência à Tração na Flexão}

A Tabela XII apresenta os resultados médios obtidos nos ensaios de resistência à tração na flexão; a Tabela XIII contém os resultados obtidos pela ANOVA.

A análise estatística dos dados de tração na flexão indicou que a variável controlável espessura gerou uma influência significativa na variável de resposta (resistência à tração na flexão). Cabe destacar que a análise do fator controlável teor de adição de fibra apresentou um nível de significância de 6,52\%, muito próximo dos 5\% (porcentagem de significância) adotado pela Análise de Variância (ANOVA), logo foi considerado como significativo nesta pesquisa.

Tabela X - Resultados médios de módulo de elasticidade

\begin{tabular}{cccc}
\hline $\begin{array}{c}\text { TEORES DE FIBRAS } \\
\left(\mathbf{g} / \mathbf{m}^{3}\right)\end{array}$ & $\begin{array}{c}\text { MÓDULO DE ELASTICIDADE } \\
\text { MÉDIO AOS 28 DIAS (GPa) }\end{array}$ & $\begin{array}{c}\text { DESVIO } \\
\text { PADRÃO } \\
(\mathbf{G P a})\end{array}$ & $\begin{array}{c}\text { COEFICIENTE DE } \\
\text { VARIÂNCIA } \\
(\mathbf{\%})\end{array}$ \\
\hline 0 & 52,18 & 14,99 & $28,732 \%$ \\
300 & 62,32 & 14,61 & $23,445 \%$ \\
600 & 35,10 & 2,02 & $5,769 \%$ \\
900 & 36,10 & 2,48 & $6,857 \%$ \\
\hline
\end{tabular}

Tabela XI - Módulo de elasticidade (ANOVA)

\begin{tabular}{ccccccc}
\hline EFEITO & SS & GDL & MS & F (CALC) & P & SIGNIFICÂNCIA \\
\hline $\begin{array}{c}\text { Teor de adição de } \\
\text { fibra }\end{array}$ & 2108,29 & 3 & 702,76 & 5,4948 & 0,00603 & S \\
Erro & 2685,8 & 21 & 127,9 & & & \\
\hline
\end{tabular}

GDL: graus de liberdade (n-1); MS: média simples; F(calc): valor calculado de F; P: nível de significância; S: valor significativo; NS: valor não significativo; $\mathrm{Se} \mathrm{P}<5 \%$ valor significativo 
Tabela XII - Resistência à tração na flexão

\begin{tabular}{cccc}
\hline $\begin{array}{c}\text { TEORES DE FIBRAS } \\
\left(\mathbf{g} / \mathbf{m}^{\mathbf{3}}\right)\end{array}$ & $\begin{array}{c}\text { RESISTÊNCIA À TRAÇÃO } \\
\text { NA FLEXÃO AOS 28 DIAS } \\
(\mathbf{M P a})\end{array}$ & $\begin{array}{c}\text { DESVIO PADRÃo } \\
\text { (MPa) }\end{array}$ & $\begin{array}{c}\text { COEFICIENTE DE } \\
\text { VARIÂNCIA } \\
(\mathbf{\%})\end{array}$ \\
\hline 0 & 2,09 & 0,1103 & 5,29 \\
300 & 2,20 & 0,2052 & 9,33 \\
600 & 2,30 & 0,2370 & 10,32 \\
900 & 2,41 & 0,2037 & 8,45 \\
\hline
\end{tabular}

Tabela XIII - Tração na flexão (ANOVA)

\begin{tabular}{ccccccc}
\hline EFEITO & SS & GDL & MS & F (CALC) & P & SIGNIFICÂNCIA \\
\hline Espessura & 0,2604 & 1 & 0,2604 & 9,418 & 0,00734 & S \\
Teor de adição de fibra & 0,2433 & 3 & 0,0811 & 2,934 & 0,06525 & S \\
$\begin{array}{c}\text { Espessura * teor de } \\
\text { adição }\end{array}$ & 0,0568 & 3 & 0,0189 & 0,385 & 0,57417 & NS \\
Erro & 0,4424 & 16 & 0,0277 & & & \\
\hline
\end{tabular}

GDL: graus de liberdade (n-1); MS: média simples; F(calc): valor calculado de F; P: nível de significância; S: valor significativo; NS: valor não significativo; $\mathrm{Se} \mathrm{P}<5 \%$ valor significativo

Com os resultados obtidos pode-se verificar um aumento de $14 \%$ da resistência à tração entre o concreto referência e o concreto com $900 \mathrm{~g} / \mathrm{m}^{3}$. A adição de fibras ao concreto, para uma fração volumétrica baixa ou moderada, não interfere na resistência mecânica do material, mas sim na tenacidade à flexão do mesmo, pois as fibras acabam amarrando as fissuras internas provocadas pela tração na flexão, sendo que tal fato comprova os acréscimos verificados nos resultados obtidos utilizando-se os maiores teores de adição (MEHTA; MONTEIRO, 2014; RAMESH; GOKULNATH; KUMAR, 2020). A Figura 4 apresenta o comportamento para o efeito do teor de fibra frente aos esforços de tração na flexão, em que se verifica uma tendência de acréscimo nessa propriedade com o incremento no teor de adição de fibra, para ambas as espessuras estudadas.

Mehta e Monteiro (2014) acreditavam que aumentando-se o teor de fibras de um elemento de concreto e, consequentemente, a aproximação das mesmas, poderia se criar uma barreira contra a propagação de fissuras, conferindo ao concreto um aumento de sua resistência à tração. Após a realização de vários experimentos, eles comprovaram que não havia um crescimento considerável desta resistência, porém já era sabido por outros estudos que as fibras melhoravam este comportamento, principalmente no estado pós-fissurado. O concreto com fibras torna-se muito tenaz, ou seja, deformável e mais resistente a impactos.

Figura 4 - Gráfico da análise estatística dos dados de tração na flexão

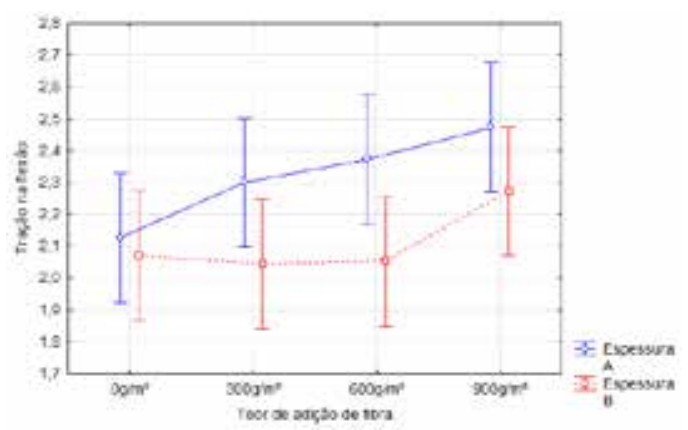


Segundo Araújo et al. (2005) e Karimipour et al. (2020), as fibras em componentes à base de cimento, em geral, apresentam dois efeitos importantes. O primeiro deles é de que elas tendem a reforçar o compósito sobre todos os modos de carregamento que induzem tensões de tração, isto é, retração restringida, na tração direta ou na flexão e cisalhamento, e, secundariamente, elas melhoram a ductibilidade e a tenacidade de uma matriz mais fraca/frágil. Johnston (2014) ainda acrescenta a importância da orientação e distribuição da fibra na matriz, ressaltando que a orientação de uma fibra, relativa ao plano de ruptura ou fissura, influencia de grande modo sua habilidade de transmitir as cargas. Uma fibra que se posiciona paralela ao plano de ruptura não tem efeito, enquanto que uma perpendicular tem efeito máximo.

Ainda, segundo análise da Figura 4, observa-se que para a espessura de $80 \mathrm{~mm}$ (espessura A) encontrou-se maiores valores de resistência do que nas placas de $100 \mathrm{~mm}$ (espessura B). Este resultado pode estar relacionado ao fato de o volume de concreto produzido para as placas de $80 \mathrm{~mm}$ ser menor em relação ao de $100 \mathrm{~mm}$, o que facilitou na hora do preparo, mistura na betoneira e moldagem dos corpos de prova. Conjuntamente a isto, segundo Mehta e Monteiro (2014), a adição de fibras em concretos gera a perda de trabalhabilidade do material.

\section{Conclusões}

Com a análise dos resultados obtidos nos ensaios realizados neste trabalho, pode-se estabelecer algumas conclusões quanto ao comportamento das propriedades analisadas (variáveis de resposta), em relação aos materiais e as variáveis controláveis.

a) As adições de diferentes teores de fibra não trouxeram nenhum ganho na resistência à compressão. Como a fibra de polipropile- no estudada é uma fibra de baixo módulo, ela influenciou diretamente no resultado do ensaio de módulo de deformação;

b) Evidenciou-se a diminuição do módulo em corpos de prova que tinham maior teor de adição devido ao fato da resistência à deformação das fibras ser menor do que a do concreto, e da perda da trabalhabilidade do material em misturas com teores mais altos de adição $\left(600 \mathrm{~g} / \mathrm{m}^{3}\right.$ e $\left.900 \mathrm{~g} / \mathrm{m}^{3}\right)$;

c) A absorção para os teores de $900 \mathrm{~g} / \mathrm{m}^{3}$ e $600 \mathrm{~g} / \mathrm{m}^{3}$ mostrou-se maior do que para os concretos dosados com $300 \mathrm{~g} / \mathrm{m}^{3}$ e sem a presença da adição;

d) Na realização do ensaio de tração na flexão verificou-se uma tendência no aumento desta resistência conforme o acréscimo no teor de fibra;

e) Pode-se analisar que com a espessura de $80 \mathrm{~mm}$ foram verificados valores maiores de resistência à tração na flexão em comparação às placas de $100 \mathrm{~mm}$ de espessura. Este fato pode ser explicado devido ao volume de concreto ser menor entre a moldagem de uma placa e outra, facilitando o preparo, mistura na betoneira e moldagem dos corpos de prova das amostras provenientes das placas com menor espessura.

O objetivo deste estudo foi verificar a influência da variação da espessura e adição de fibras frente a esforços de tração na flexão. O estudo identificou que o aumento do teor de adição de fibras em relação ao indicado pelo fabricante frente aos esforços de tração na flexão foi significativo, porém este aumento de teor implica na perda de trabalhabilidade da mistura. No desenvolvimento da dosagem experimental evidenciou-se que a adição de teores de fibras a partir de $600 \mathrm{~g} / \mathrm{m}^{3}$ influencia diretamente na trabalhabilidade da mistura, tornando mais difícil seu manuseio e preparo, 
e diminuindo significativamente a habilidade do concreto de deslizar pelas formas.

Contudo, observou-se que a adição de teor de fibra da ordem de $900 \mathrm{~g} / \mathrm{m}^{3}$ mostrou-se eficiente frente aos esforços de tração na flexão, porém, para os outros parâmetros estudados, este teor teve influência negativa, cabendo a elaboração de uma nova dosagem de concreto autoadensável mediante a análise de diferentes teores de aditivos, a fim de se desenvolver uma dosagem que resulte em uma melhor trabalhabilidade para a mistura.

\section{REFERÊNCIAS}

ARAÚJO, C, T, F.; FALCÃO, S, C, M.; BARBOZA, A, S, R. Influência da Adição de Fibras de Polipropileno no Comportamento das juntas de Argamassa. Maceió, 2005.

ASSOCIAÇÃO BRASILEIRA DE NORMAS TÉCNICAS. NBR 12142: Concreto - Determinação da resistência à tração na flexão de corpos de prova prismáticos. Rio de Janeiro, 2010.

ASSOCIAÇÃO BRASILEIRA DE NORMAS TÉCNICAS. NBR 15823/2: Concreto autoadensável: Determinação do espalhamento e do tempo de escoamento - Método do cone de Abrams. Rio de Janeiro, 2017.

ASSOCIAÇÃO BRASILEIRA DE NORMAS TÉCNICAS. NBR 15823/4: Concreto autoadensável: Determinação da habilidade passante - Método da caixa L. Rio de Janeiro, 2017.

ASSOCIAÇÃO BRASILEIRA DE NORMAS TÉCNICAS. NBR 15823/5: Concreto autoadensável: Determinação da viscosidade - Método do funil V. Rio de Janeiro, 2017.

ASSOCIAÇÃO BRASILEIRA DE NORMAS TÉCNICAS. NBR 16055: Paredes de concretos moldadas no local da construção. Rio de Janeiro, 2012.

ASSOCIAÇÃO BRASILEIRA DE NORMAS TÉCNICAS. NBR 5739: Concreto - Ensaios de compressão de corpos de prova cilíndricos. Rio de Janeiro, 2018.

ASSOCIAÇÃO BRASILEIRA DE NORMAS TÉCNICAS. NBR 8522: Concreto - Determinação do módulo estático de elasticidade à compressão. Rio de Janeiro, 2017.

ASSOCIAÇÃO BRASILEIRA DE NORMAS TÉCNICAS. NBR 9779: Argamassa e concreto endurecidos - Determinação da absorção de água por capilaridade. Rio de Janeiro, 2012.

FIGUEIREDO, A. D. Concretos reforçado com fibras. 2011. Tese (Livre-Docência) Departamento de Engenharia de Construção Civil, USP, São Paulo, 2011.

JOHNSTON, C. D. Fiber-reinforced cements and concretes. Crc Press, 2014.

JUNIOR DOBBIN, E.S.; ROCHA, L.S.F.; Estudo de concreto com adição de fibra de polipropileno para controle da fissuração. 2011. Monografia - Universidade da Amazônia, Belém, 2011.

KARIMIPOUR, A.; GHALEHNOVI, M.; BRITO, J.; ATTARI M. The effect of polypropylene fibres on the compressive strength, impact and heat resistance of self-compacting concrete. Structures, $\mathrm{n}$. 25, p. 72-87, 2020.

LIU, X.; WU, T.; YANG, X.; WEI, H. Properties of self-compacting lightweight concrete reinforced with steel and polypropylene fibers. Construction and Building Materials, n. 226, p. 388-398, 2019. 
MEHTA, P.K.; MONTEIRO, P.J.M. Concreto: Microestrutura, Propriedades e Materiais. 3.ed. São Paulo: Ibracon, 2014.

RAMESH, B.; GOKULNATH, V.; KUMAR, M. R. Detailed study on flexural strength of polypropylene fiber reinforced self-compacting concrete. Materials Today: Proceedings, n. 22, p. 1054-1058, 2020.

RODRIGUES, P. PF; MONTARDO, J. P. A influência da Adição de Fibras de Polipropileno nas Propriedades dos Concretos para Pisos e Pavimentos. In: $44^{\circ}$ Congresso Brasileiro do Concreto. Ibracon, Belo Horizonte/Brasil. 2002.

SRIDHAR, R.; PRASAD, R. Mechanical and Dynamic Properties of Polypropylene Fiber Reinforced Concrete. Structural Integrity Assessment - Proceedings of ICONS 2018, PRAKASH, R. V.; KUMAR, R. S.; NAGESHA, A.; SASIKALA, G.; BHADURI, A. K. (Eds). Springer, p. 361374, 2018.

TANESI, J.; FIGUEIREDO, A. D. Fissuração por retração em concretos reforçados com fibras de polipropileno (CRFP). Boletim Técnico. Escola Politécnica da Universidade de São Paulo, 1999. TUTIKIAN, B.F.; MOLIN, D.C.D. Concreto Auto-adensável. 1. ed. São Paulo: Pini, 2008. 
